\title{
НОВЫЕ РЕАГЕНТЫ ДЛЯ ПОДГОТОВКИ НЕФТИ в ПРОМЫСЛОВЫХ УСЛОВИЯХ
}

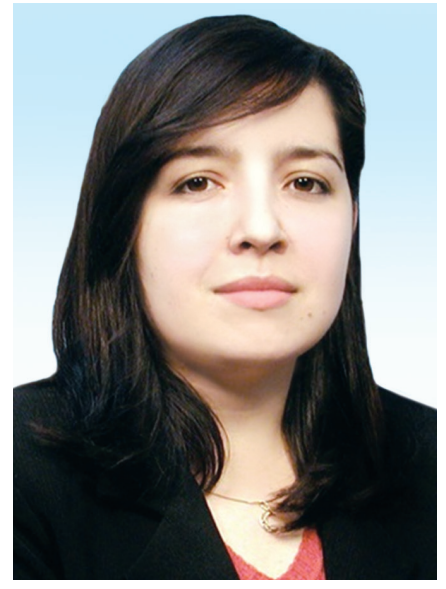

Ж.К. НАДИРОВА, кандидат технических наук, доцент кафедры «Биотехнология», https://orcid.org/0000-00019045-0838

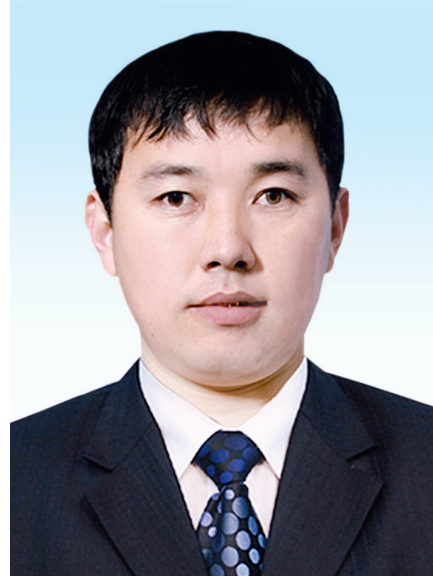

Н.Ш. ОТАРБАЕВ, $\mathrm{PhD}$, старший преподаватель кафедры «Нефтегазовое дело», https://orcid.org/0000-00021914-398X

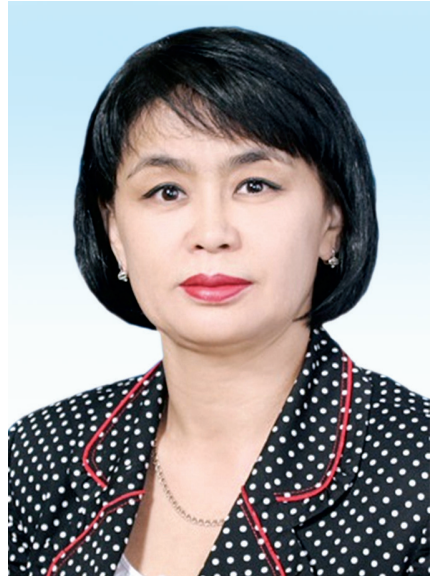

Г.Ж. БИМБЕТОВА, кандидат технических наук, профессор кафредры «Нефтегазовое дело», https://orcid.org/0000-00031859-5551

К.С. НАДИРОВ*, доктор химических наук, профессор кафедры «Нефтегазовое дело», https:// orcid.org/0000-0003-3323-8245

М.К. ЖАНТАСОВ, кандидат технических наук, профессор, заведующий кафедрой «Нефтегазовое дело», https://orcid.org/0000-0001-5633-1640

ЮЖНО-КАЗАХСТАНСКИЙ УНИВЕРСИТЕТ ИМ. М. АУЭЗОВА, Республика Казахстан, 160012, г. Шымкент, проспект Тауке хана, 5

Рассмотрены вопросы получения новых химических реагентов и их использование для разрушения водонефттяных эмульсий в промысловых условиях при подготовке парафинистой нефтти. Целью проведенных исследований являлось создание эфффективных реагентов для обезвоживания и обессоливания парафринистых нефтей, снижения вязкости водонефртяной эмульсии. Предлагается способ смешения поверхностно-активных веществ (ПАВ) различного строения с исходными реагентами, подбор составов $c$ различными свойствами. При этом в состав ПАВ вводится несколько индивидуальных соединений, которые в смеси проявляют синергетический эфрфект. Предлагаемые композиции обладают комплексом свойств, - как результат взаимодействия компонентов смеси. Проведенными исследованиями выявлен состав реагента, включающего неионогенный деэмульгатор (этерифицированные жирные кислоты ,выделенные из хлопкового соапстока), а также сульфанол, синтанол АЛМ-10 и растворитель при определенных их соотношениях. Лабораторные испытания новой композиции, выполненные на нефти месторождения Ащысайи модельных эмульсиях, показали, что композиция относится к

\footnotetext{
* Адрес для переписки. E-mail: nadirovkazim@mail.ru
} 
эффрективным реагентам для разрушения водонефтяных эмульсий. Было установлено, что сульфранол проявляет хорошо выраженные моющие свойства в составе композиции. При обезвоживании нефтяных эмульсий выявлен синергизм деэмульгирующего действия разработанного состава при определенном соотношении используемых компонентов.

Исследовалась стабильность эмульсии в течение 3 часов при температуре $20 \mathrm{u}$ $60^{\circ} \mathrm{C}$. Установлено, что для нефртяной эмульсии в промежутке времени от 30 минут до 3 часов, количество отделившейся воды составило от 30 до 60\% в зависимости от температуры. Эффрективность действия реагента предложенного состава показана также на микроскопических снимках. По качеству воздействия на обезвоживание нефртяной эмульсии реагент не уступает известным составам, используемым для деэмульсации парафринистой нефрти. Поэтому его фрункциональные возможностей представляет практический интерес для промысловой подготовки скважинной продукции на месторождениях по добыче и подготовке нефти.

КЛЮЧЕВЫЕ СЛОВА: нефть, эмульсия, асфральтены, парафины, деэмульгатор, соапсток, этерифицированные жирные кислоты, обезвоживание.

\section{КӘСІПШІЛІК ЖАҒДАЙЛАРДА МҰНАЙДЫ ДАЙЫНДАУҒА АРНАЛҒАН ЖАНА РЕАГЕНТТЕР}

Ж.К. НАДИРОВА, техника ғылымдарының кандидаты, «Биотехнология»кафедрасының доценті, https://orcid.org/0000-0001-9045-0838;

H.Ш. ОТАРБАЕВ, PhD, «Мұнайгаз ісі» кафедрасының аға оқытушысы, https://orcid.org/0000-00021914-398X;

Г.Ж. БИМБЕТОВА, техника ғылымдарының кандидаты, Мұнайгаз ісі» кафедрасының, профессоры, https://orcid.org/0000-0003-1859-5551;

К.С. НАДИРОВ, химия ғылымдарының докторы, «Мұнайгаз ісі» кафедрасының профрессоры, https:// orcid.org/0000-0003-3323-8245;

М.К. ЖАНТАСОВ, техника ғылымдарының кандидаты, «ұұнайгаз ісі» кафредрасының меңгерушісі, https://orcid.org/0000-0001-5633-1640

М. ӘУЕЗОВ АТЫНДАҒЫ ОНТҮСТІК ҚАЗАҚСТАН УНИВЕРСИТЕТІ,

Қазақстан Республикасы, 160012, Шымкент қ., Тәуке хан даңғылы, 5

Мақалада жаңа химиялық реагенттерді алу және оларды кәсіпшілік жағдайда парафринді мұнайды дайындау кезінде сумұнай эмульсияларын жою үшін пайдалану мәселелері қарастырылған. Жүргізілген зерттеулердің мақсаты парафинді мұнайларды сусыздандыру және тұзсыздандыру, сумұнай эмульсиясының кешенді тұтқырлығын төмендету үшін реагенттің тиімді құрамын жасау болып табылады. Бастапқы компоненттердің белгілі бір жиынтығы болған кезде әр түрлі құрылымдағы беттік-активті заттарды (БАЗ) ығыстыру және әртүрлі қасиеттері бар реагенттердің құрамын таңдау әдісі ұсынылады. БАЗ-тың құрамына қоспада синергетикалық әсер көрсететін бірнеше жеке қосылыстар енгізіледі. Ұсынылған композициялар олардың бірге әрекеттесуінің нәтижесі болып табылатын бірқатар қасиеттерге ие. Зерттеулер нәтижесінде құрамында иондық емес деэмульгатор бар тиімді реагент құрамы алынды, иондық емес деэмульгатор ретінде мақта соапстогынан бөлінген, этерифрицирленген май қышқылдары,сондай-ақ сульфанол, АЛМ-10 синтанол және белгілі бір қатынастардағы еріткіш қолданылды. Ащысай кен орнының мұнайында және модельдік эмульсияларда жасалған жаңа композицияның зертханалық сынақтары, алынған композицияның сумұнай эмульсияларын жоюға арналған реагенттерге жататынын көрсетті. Сульфранол реагенті композиция құрамында жуу қасиеттерін айқын көрсететіні анықталды. Мұнай эмульсияларын белгілі бір диапазонында сусыздандыру кезінде алынған құрамның деэмульгирлеуші әсерінің синергизмі анықталды.

20 және $60^{\circ} \mathrm{C}$ температурада 3 сағат бойы эмульсияның тұрақтылығы зерттелді. Мұнай эмульсиясы үшін 30 минуттан 3 сағатқа дейінгі уақыт аралығында бөлінген судың мөлшері мұнай температурасына байланысты 30-дан 60\%- ға дейін екендізі анықталды. Ұсынылған реагент құрамының тиімділігі микроскопиялық суреттерде де көрсетілген. Су- 
сыздандыру тиімділігі бойынша реагент парафринді мұнайдың деэмульсациясы үшін белгілі құрамдардан кем түспейді. Деэмульгирлеу қабілетін сақтай отырып, оның фуункционалдық мүмкіндіктерін кеңейту мұнай өндіру және дайындау бойынша кен орындарында ұңғымалық өнімді кәсіпшілік дайындау үшін практикалық қызығушылық тудырады.

ТҮЙІн СӨзДЕР: мұнай, эмульсия, асфральтендер, парафриндер, деэмульгатор, соапсток, этерифицирленген май қышқылдары, сусызданыру.

\section{NEW REAGENTS FOR OIL TREATMENT IN THE FIELD CONDITIONS}

ZH.K. NADIROVA, candidate of technical sciences, professor of Biotechnoly department, https://orcid. org/0000-0001-9045-0838;

N.ZH. OTARBAEV, PhD, senior lecturer of the «Oil and gas business»department, https://orcid.org/00000002-1914-398X;

G.ZH. BIMBETOVA, candidate of technical sciences, professor of «Oil and gasbusiness» department, https://orcid.org/0000-0003-1859-5551;

K.S. NADIROV, doctor ofchemical sciences, professor of «Oil and gas business» department, https:// orcid.org/0000-0003-3323-8245;

M.K. ZHANTASOV, candidate technical sciences, professor, head of the department of «Oil and gas business», https://orcid.org/0000-0001-5633-1640

\section{AUEZOV SOUTH KAZAKHSTAN UNIVERSITY,} 160012, Shyment City, Tauke khan avenue, 5

The article discusses the issues of obtaining new chemical reagents and their use for the destruction of water-oil emulsions in the field during the preparation of paraffinic oil. The purpose of the research was to create an effective composition of a reagent for dehydration and desalting of paraffinic oils, reducing the complex viscosity of an oil-water emulsion. A method is proposed for the displacement of surfactants (surfactants) of various structures in the presence of a certain set of initial components and the selection of reagent compositions with different properties.

The surfactant contains several individual compounds in a mixture that exhibit a synergistic effect. The proposed compositions have a set of properties resulting from their combined action. As a result of the studies, an effective composition of the reagent was obtained, including a nonionic demulsifier, which was used as esterified fatty acids isolated from cotton soap stock, as well as sulfanol, ALM-10 syntanol and a solvent at certain ratios.Laboratory tests of the new composition, carried out on oil from the Ashysay field and model emulsions, showed that the composition belongs to reagents for the destruction of oil-water emulsions. It was found that the sulfanol reagent exhibits pronounced detergent properties in the composition. The synergism of the demulsifying action of the developed composition during dehydration of oil emulsions in a certain range of ratios of certain components has been revealed.

Studied the stability of the emulsion for 3 hours at a temperature of 20 and $60^{\circ} \mathrm{C}$. It was found that for the oil emulsion in the time interval from 30 minutes to 3 hours, the amount of separated water was from 30 to $60 \%$, depending on the oil temperature. The effectiveness of the proposed composition of the reagent is also shown on microscopic images. In terms of the efficiency of dehydration, the reagent is not inferior to known compositions for the demulsification of paraffinic oil. Expanding its functionality while maintaining demulsifying ability is of practical interest for field preparation of well products in oil production and treatment fields.

KEY WORDS: oil, emulsion, asphaltenes, paraffins, demulsifier, soap stock, esterified fatty acids, dehydration.

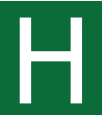

ефтегазовая отрасль является одной из приоритетных при формировании бюджета нефтедобывающих стран. В нефтяной отрасли непосредственно или косвенно занята значительная часть трудоспособного населения, и от ее успехов напрямую зависит благосостояние народов стран, добывающих углеводороды. 
Хотя Казахстан не является членом организации стран-экспортеров нефти, однако, объемы добычи нефти в стране ежегодно увеличиваются и составляют более 80 млн т ежегодно. События последних лет во многих странах мира привели к снижению их экономической активности и оказали негативное влияние на спрос и мировые цены на углеводороды. Однако считаем, что такая ситуация на рынке будет сохраняться не вечно и со временем спрос на углеводороды значительно повысится. Поэтому масштабное внедрение новых инновационных технологий по добыче, подготовке, транспортировке и переработке нефти дадут эффект и в ближайшее время, и в долгосрочный перспективе [1].

В настоящее время на большинстве месторождений Казахстана вместе с нефтью добывается до 90\% воды, образующей с ней стойкие водонефтяные эмульсии, стабилизированные природными поверхностно-активными веществами (ПАВ) и смолами. Поэтому при добыче нефти, в.ч. и парафинистой, и ее подготовке к первичной обработке в промысловых условиях, основной проблемой является разрушение устойчивых водонефтяных эмульсий. Этот процесс значительно усложняет добычу нефти, а соленые воды негативно влияют на работу нефтеперекачивающего оборудования и трубопроводные коммуникаций. Последствием являются процессы коррозии, как нефтепромыслового оборудования, так и оборудования предприятий по переработке углеводородного сырья. Из-за высокой устойчивости таких эмульсий их разрушения удается достичь только с помощью деэмульгаторов и температурной обработки. Сложность подготовки к транспортировке добываемого нефтяного сырья становится все более заметной с увеличением добычи парафинистой нефти, поэтому исследование специальных деэмульгаторов для нее очень важно. Несмотря на наличие широкого ассортимента существующих деэмульгаторов в настоящее время их применение на практике не всегда дает желаемые результаты. Кроме того, относительно высокая стоимость используемых в промысловых условиях деэмульгаторов отражается, естественно, на себестоимости нефти [2-4].

В работе [5] приведен анализ состояния проблемы подготовки (деэмульсации) казахстанских нефтей, в том числе парафинистых. Отмечается, что около 70\% добываемой в мире нефти представляет собой устойчивые дисперсные системы типа вода в нефти. Что же касается добываемой в Казахстане нефти, то она, как отмечено выше, имеет значительно большую обводненность. Одним из эффективных направлений в создании новых деэмульгаторов является компаундирование поверхностно-активных веществ различного строения, которые позволяют, при наличии определенного набора исходных компонентов, получить составы со свойствами направленного действия. Этот путь позволяет усилить наиболее важные характеристики реагентов и расширить их функциональное действие [6-10].

В настоящее время для снижения себестоимости конечной продукции при получении химических реагентов подготовки нефти целесообразным является использование вторичных ресурсов и отходов производств. В данной работе обозначенные выше задачи решаются комплексно за счет использования побочных продуктов переработки масложирового производства, а именно, жирных кислот, полученных вакуумной дистилляцией соапстока, для последующего получения на их основе композиционных деэмульгаторов $[11,12]$. 
Следует отметить, что для получения химических реагентов для разрушения водонефтяных эмульсий во всех случаях необходимы жирные кислоты, которые являются ценным продуктом, и находят свое применение в самых различных областях промышленности [13,14].

В промышленном масштабе синтетические жирные кислоты получают в результате реакции окисления насыщенных углеводородов (алканов). Реакцию окисления алканов до жирных кислот проводят при повышенной температуре, так как насыщенные углеводороды при нормальной температуре трудно вступают в химические реакции. Обычно сырьем для получения синтетических жирных кислот служат фракции керосиновых и масляных дистиллятов, а также твердые прарафины. Так как парафины состоят в основном из предельных углеводородов, то есть алканов нормального строения, поэтому при окислении алканов получаются, главным образом, насыщенные карбоновые кислоты с неразветвленной цепью. В промышленности окислению подвергают углеводороды, входящие в состав средней по температуре плавления фракции парафина, т. е. содержащие от 12 до 20 атомов углерода в молекуле. Через расплавленный парафин при $110^{\circ} \mathrm{C}$ в течение определенного времени продувают воздух в присутствии катализатора перманганата калия, который влияет на направление химической реакции и определяет состав целевого продукта [15-17].

В работах, проведенных нами ранее, исходные жирные кислоты нами были получены путем омыления гудрона (кубового остатка) дистилляции жирных кислот масла хлопчатника. После омыления и соответствующей обработки жирные кислоты экстрагировались бензином. Однако предварительные технико-экономические расчеты показали, что этот путь для получения исходных жирных кислот с целью их этерификации является трудоемким и затратным, не всегда обеспечивает селективного выхода целевого вещества. Более предпочтительным является использование в качестве исходных реагентов жирных кислот, полученных вакуумной дистилляцией непосредственно из соапстока. Эти кислоты обеспечивают высокие выходы целевого вещества и его селективность. Кроме того, состав жирных кислот вакуумного дистиллята содержит значительное количество ненасыщенных жирных кислот, которые являются более ценным сырьем, так как являются более реакционно-способными при их оксиэтилировании и этерификации [18].

Целью данной статьи является обобщение экспериментальных данных по некоторым проблемам подготовки нефти и возможные пути решения их в условиях конкурентной борьбы на рынке деэмульгаторов.

Объектами исследования являлись композиции разного состава, созданные на основе этерифицированных жирных кислот (ЭЖК), полученных непосредственно при вакуумной дистилляции жирных кислот хлопкового соапстока. Состав вакуумного дистиллята, установленный нами методом газожидкостной хроматографии (ГЖХ), представлен ниже. Ненасыщенные кислоты, мас.\%,: линолевая - 31,1; линоленовая - 25,2; олеиновая - 19,3. Насыщенные кислоты: пальмитиновая - 18,0; стеариновая - 2,1; миристиновая - 1,4;арахидиновая - 0,5. Именно этот состав был выбран для получения этерифицированных жирных кислот (ЭЖК), которые получали в реакторе высокого давления РВД-2-150 по разработанной авторами технологии в ЮКУ им. М. Ауэзова [18]. 
Сульфанол и синтанол АЛМ-10 для исследований были приготовлены соответственно по методикам ТУ 2481-004-48482528-99 и ТУ-2483-003-71150986-2006. В качестве растворителя использовали Нефрас Ар 120/200 по ТУ 38.101809-90. Для сравнительной оценки в качестве прототипа при создании нового реагента широкого спектра действия был выбран деэмульгатор, полученный нами ранее [9]. Лабораторные испытания композиций выполнялись на нефтях месторождения Ащысай и модельных эмульсиях на их основе по соответствующей методике.

Поступающая эмульсия отбиралась с пробоотборника установки комплексной подготовки нефти (УКПН), установленного на общем коллекторе до точки подачи деэмульгатора. В пробы эмульсии дозировали испытываемые деэмульгаторы с определенными удельными расходами нефти, затем пробы встряхивали 300 раз в течение 2 мин и оставляли на отстаивание в течение 90 минут при температуре $40^{\circ} \mathrm{C}$. Через определенные промежутки времени фиксировали количество выделяющейся воды и качество раздела фаз «нефть-вода». После отстоя выделившуюся воду удаляли специальным шприцем, оставшуюся нефть вместе с промежуточным слоем центрифугировали в течение 5 мин при частоте вращения ротора 2000 мин $^{-1}$. На центрифуге ОПн-12 с ротором РУ-180 определяли остаточное содержание воды в нефти и промежуточном слое, причем оставшаяся вода после центрифугирования выделялась в виде самостоятельной фазы и остаточной неразрушенной эмульсии. Чем больше остаточной воды в нефти остается в виде неразрушенной эмульсии, тем ниже эффективность действия деэмульгатора, тем больше вероятность образования и накопления промежуточных слоев в отстойной емкости. В контрольной пробе (без реагента) до и после отстоя также методом центрифугирования определяли агрегативную устойчивость эмульсии. Микроскопия водонефтяных эмульсии выполнялась на тринокулярном микроскопе марки «Levenhuk 870T».

На основании проведенных экспериментов был подобран состав для обезвоживания и обессоливания нефти: ЭЖК - 40-50\%; хлопковый соапсток - $10-15 \%$; ПАВ с моющим эффектом - сульфанол - 10-15\%; ПАВ со смачивающим эффектом - синтанол АЛМ-105-10 и растворитель (Нефрас Ар 120/200) - остальное.

B таблице 1 приведены некоторые составы композиционных деэмульгаторов, а результаты проведенных испытаний эффективности предлагаемых составов в таблицах 2,3.

При использовании предлагаемого нами реагента в процессах глубокого обезвоживания и обессоливания смеси нефтей с разнородными эмульсиями, а также парафинистой нефти было показано, что полученные реагенты являются эффективными.

Из данных, приведенных в таблице 2, следует, что деэмульгирующая эффективность реагентов при дозировке 35 г/т высокая и не уменьшается при изменении состава, причем в данном случае уменьшение содержания сульфанола, синтанола АЛМ-10 и соапстока (и даже их отсутствие: примеры 7, 8 и 11), не вызывает снижения эффективности состава, что связано,по-видимому, с тем, что по эффективности обезвоживания композиция, которая содержитвсвоем составе ЭЖК является эффективным реагентом для разрушения водонефтяной эмульсии парафинистой нефти. При снижении содержания ЭЖК деэмульгирующая эффективность снижается 


\section{ДОБЫЧА}

Таблица 1 - Данные по составам композиционных деэмульгаторов

\begin{tabular}{|c|c|c|c|c|}
\hline \multirow{2}{*}{$\begin{array}{l}\text { Номер } \\
\text { состава }\end{array}$} & \multicolumn{4}{|c|}{ Содержание компонентов, мас. \% } \\
\hline & ЭЖК & Сульфанол & $\begin{array}{c}\text { Синтанол } \\
\text { АЛМ-10 }\end{array}$ & Соапсток \\
\hline \multicolumn{5}{|c|}{ Растворитель Нефрас Ар 120/200 } \\
\hline 1 & 40 & 10 & 5 & 15 \\
\hline 2 & 50 & 15 & 10 & 12 \\
\hline 3 & 45 & 12 & 8 & 10 \\
\hline 4 & 20 & 12 & 8 & 10 \\
\hline 5 & 0 & 12 & 8 & 10 \\
\hline 6 & 65 & 12 & 8 & 10 \\
\hline 7 & 45 & 0 & 8 & 10 \\
\hline 8 & 45 & 5 & 0 & 10 \\
\hline 9 & 45 & 20 & 15 & 10 \\
\hline 10 & 45 & 12 & 8 & 5 \\
\hline 11 & 45 & 12 & 8 & 0 \\
\hline 12 & 45 & 12 & 8 & 30 \\
\hline
\end{tabular}

Таблица 2 - Данные, полученные по деэмульгирующей эффективности композиций при дозировке 35 г/т в зависимости от их состава

\begin{tabular}{|c|c|c|c|}
\hline $\begin{array}{c}\text { Номер } \\
\text { примера }\end{array}$ & $\begin{array}{c}\text { Остаточное } \\
\text { содержание } \\
\text { воды в нефти, \% } \\
\text { мас. }\end{array}$ & $\begin{array}{c}\text { Остаточное } \\
\text { содержание } \\
\text { солей в нефти, } \\
\text { мг/л }\end{array}$ & $\begin{array}{c}\text { Скорость } \\
\text { деэмульсации } \\
\text { до остаточного } \\
\text { содержания воды 2\%, } \\
\text { мин }\end{array}$ \\
\hline прототип & 0,5 & 40 & 98 \\
\hline 1 & 0,5 & 40 & 30 \\
\hline 2 & 0,5 & 40 & 28 \\
\hline 3 & 0,5 & 40 & 31 \\
\hline 4 & 4,0 & 120 & 110 \\
\hline 5 & 6,0 & 160 & 90 \\
\hline 7 & 0,5 & 41 & 36 \\
\hline 8 & 0,5 & 42 & 45 \\
\hline 11 & 0,5 & 44 & 34 \\
\hline 12 & 0,5 & 45 & 34 \\
\hline
\end{tabular}

(примеры 4 и 5), при их отсутствии реагент проявляет свойства слабого деэмульгатора за счет наличия в составе других, менее эффективных ПАВ - сульфанола и синтанола АЛМ-10. Скорость деэмульсации при оптимальном составе композиции по сравнению с прототипом повышается более чем в полтора раза.

Результаты показали, что иначе проявляется влияние изменения соотношения компонентов на реологические свойства эмульсий (таблица 3). Комплексная вязкость при введении в состав деэмульгатора соапстока снижается в 2,5-4 раза, но только до содержания 15 масс. \%. При повышении содержания соапстока выше 18 масс.\% комплексная вязкость водонефтяной эмульсии вновь повышается (пример 12). В 
Таблица 3 - Эффективность снижения комплексной вязкости водонефтяной эмульсии

\begin{tabular}{|c|c|c|c|}
\hline \multirow{2}{*}{$\begin{array}{c}\text { Номер примера по } \\
\text { таблице 1 }\end{array}$} & \multicolumn{3}{|c|}{$\begin{array}{c}\text { Комплексная (вязкая и упругая) вязкость, МПа·с } \\
\text { приемпратуре, }{ }^{\circ} \text { С }\end{array}$} \\
\cline { 2 - 4 } & $\mathbf{5}$ & $\mathbf{1 5}$ & $\mathbf{2 5}$ \\
\hline $\begin{array}{c}\text { Исходная модельная } \\
\text { эмульсия }\end{array}$ & 20100 & 9200 & 4500 \\
\hline Прототип & 20000 & 9300 & 4600 \\
\hline 1 & 8000 & 4500 & 1800 \\
\hline 2 & 7000 & 3500 & 1200 \\
\hline 3 & 5000 & 2000 & 1000 \\
\hline 11 & 19000 & 9000 & 4200 \\
\hline 12 & 14000 & 8100 & 3500 \\
\hline 5 & 20200 & 9400 & 4700 \\
\hline 7 & 18900 & 8800 & 4400 \\
\hline 8 & 19500 & 9100 & 4500 \\
\hline
\end{tabular}

случае отсутствия соапстока в составе деэмульгатора (пример 11) или отсутствия других компонентов (примеры 7 и 8), снижения комплексной вязкости водонефтяной эмульсии практически не происходит, что подтверждает функциональное назначение соапстока в составе композиции (регулирование реологических свойств) и возникновение синергетического эффекта относительно реологических свойств модельных эмульсий за счет оптимального соотношения всех присутствующих компонентов.

Полученные данные свидетельствуют о том, что соапсток отмывает менее 50\% адсорбционного углеводородного слоя с поверхности частиц механической примеси (глины). Следовательно, при разрушении водонефтяной эмульсии с применением только одного соапстока твердые частицы всего лишь частично будут переходить с границы раздела в водную фазу по причине низкой их моющей способности. Это в свою очередь, как правило, приводит к образованию стойких промежуточных слоев, концентрированных механическими примесями на стадии обезвоживания нефти. Реагент сульфанол проявляет выраженные моющие средства. Было установлено, что синергизм деэмульгирующего действия разработанного состава при обезвоживании нефтяных эмульсий в определенном диапазоне соотношений определенных компонентов обусловлен экстремальным изменением поверхностного натяжения и смачивающего действия в области мицеллообразования.

Для исследования стабильности водонефтяной эмульсии была выбрана искусственно приготовленная нефтяная эмульсия Ашисайского месторождения (рисунок 1). Исследовалась стабильность 10\%-ной эмульсии в течение 3 часов при температуре $20^{\circ} \mathrm{C}$. Было установлено, что для нефтяной эмульсии в промежутке времени 


\section{ДОБЫЧА}

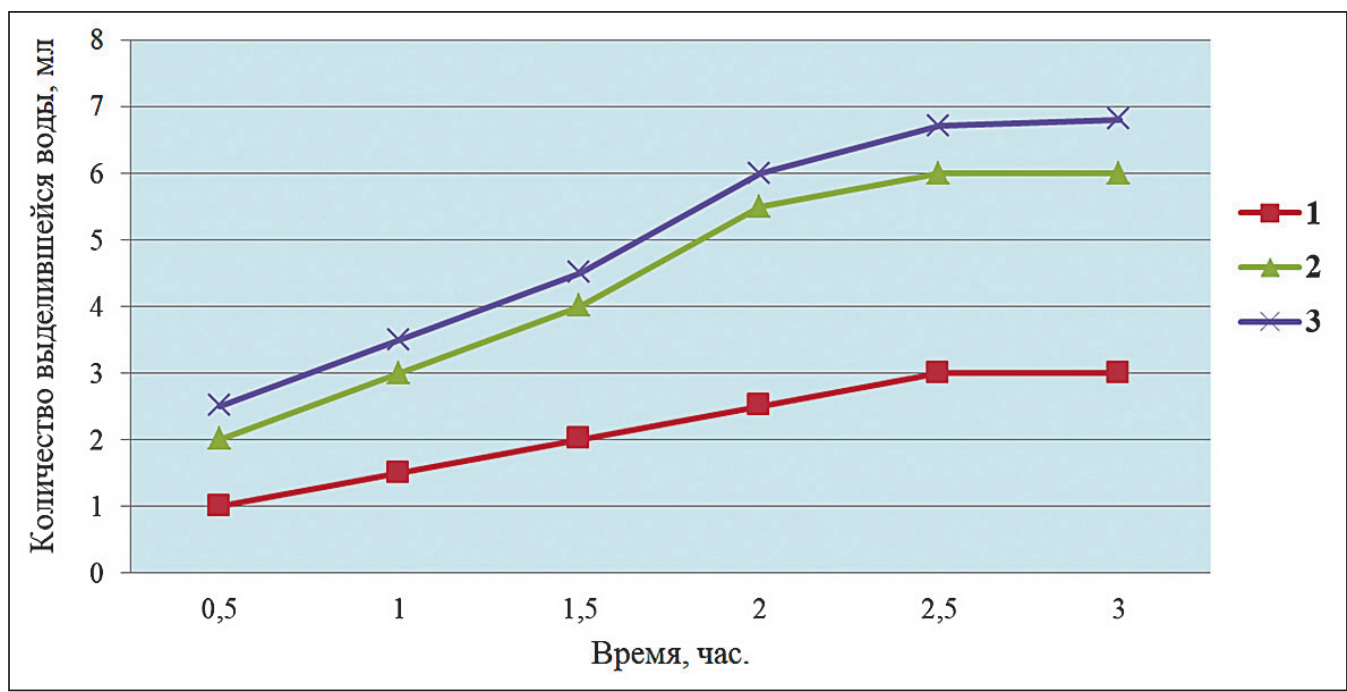

Рисунок 1 - Изменение стабильности водонефтяной эмульсии (10\%) месторождения Ащысай при температуре $20^{\circ} \mathrm{C}$ :

1 - эмульсия; 2 - эмульсия+деэмульгатор; 3 - эмульсия+ деэмульгатор+нафтенат натрия

от 30 минут до 3 часов (кривая 1), количество отделившейся воды составило $30 \%$. Для эмульсии с добавлением деэмульгатора при таких же условиях количество выделившейся воды составило $60 \%$ (кривая 2), а с добавлением деэмульгатора и, дополнительно, нафтената натрия при таких же условиях количество выделившейся воды составило 68\%. Соотношение реагент: нафтенат натрия составляет 0,4:0,6.

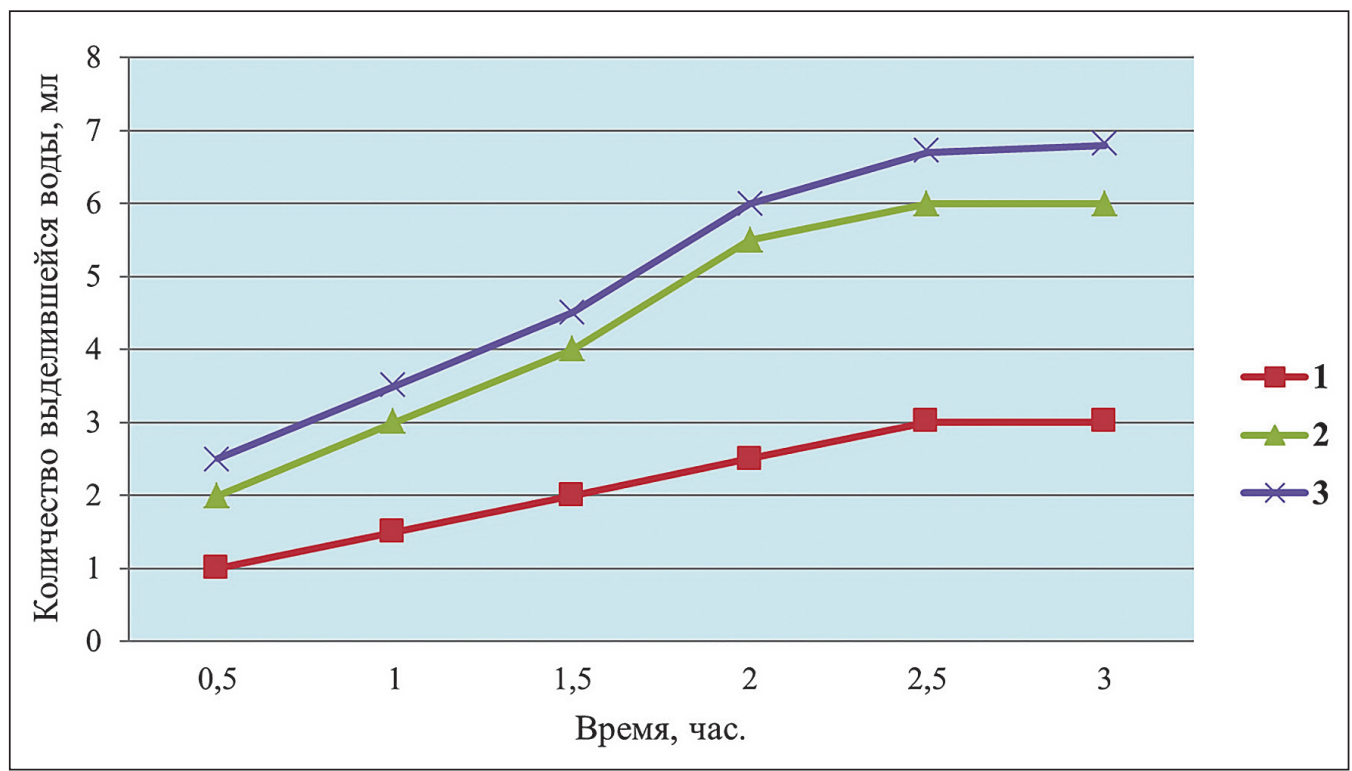

Рисунок 2 - Изменение стабильности водонефтяной эмульсии (10\%) месторождения Ащысай при температуре $60^{\circ} \mathrm{C}$ :

1 - эмульсия; 2 - эмульсия + деэмульгатор; 3 - эмульсия + деэмульгатор + нафртенат натрия 
Таким образом, при одновременном присутствии в данном составе ЭЖК и нафтената натрия, разрушение эмульсии происходит значительно быстрее (кривая 3), за счет синергетического эффекта в составе композиции.

При исследовании стабильности 10\%-ной эмульсии в течение 3 часов при температуре $60^{\circ} \mathrm{C}$ эффект разрушения эмульсии значительно ускорился и составил соответственно 47, 70 и 74\% (рисунок 2).

Эффективность действия композиционного состава исследовалась также с использованием микроскопамарки «Levenhuk 870T». Из данных рисунка 3 видно, что в начальный момент на микроскопических снимках видны более мелкие капли водонефтяных эмульсий (a), после добавления реагента ЭЖК при соответствующей дозировке происходит разрушение эмульсии и укрупнение их (коалесценция) в более крупные частицы (б).

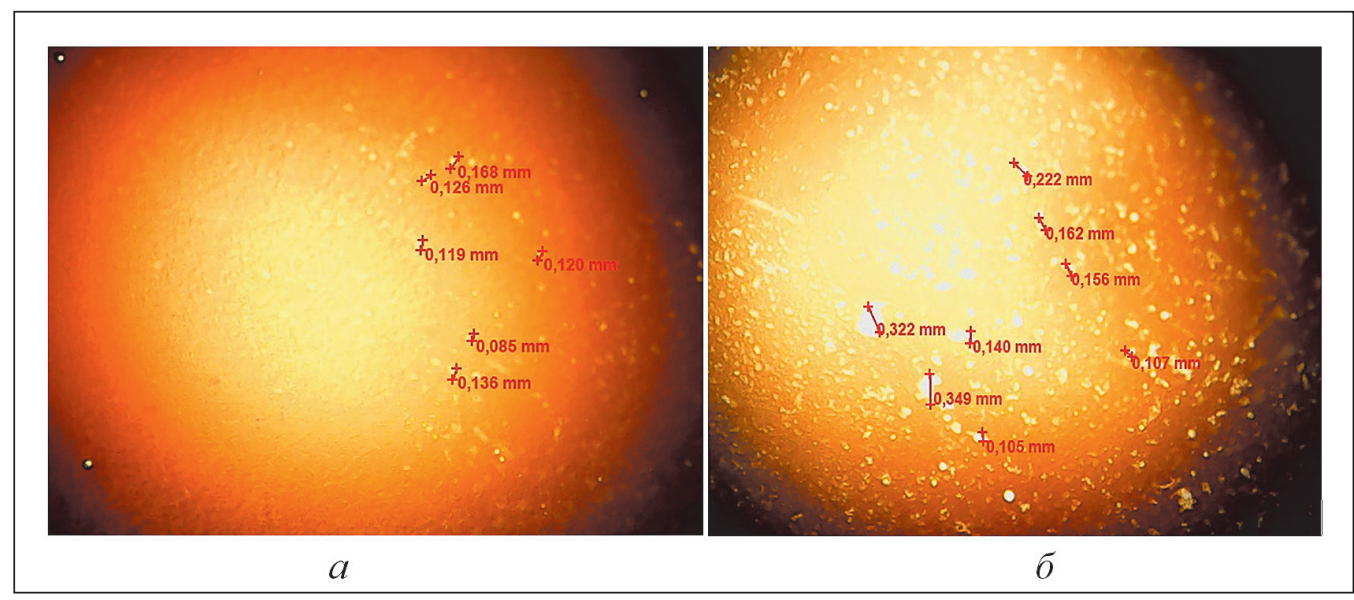

Рисунок 2 - Микроскопические снимки водонефтяной эмульсии месторождения Ащысай: а - без реагента; б - с добавлением реагента ЭЖК

Оптимальная дозировка деэмульгатора составляет $30-35$ г/т, при уменьшении дозировки снижаются все показатели эффективности реагента, при повышении содержания соапстока выше 18\% комплексная вязкость водонефтяной эмульсии повышается.

Для определения способности образования критических эмульсий в воде и гексане была исследована зависимость оптической плотности раствора от температуры (рисунок 4). При введении в водонефтяную эмульсию реагента, являющегося стабилизатором эмульсий противоположного типа, наблюдается обращение фаз эмульсии. Добавление реагента будет приводить к снижению межфазного натяжения на границе раздела «вода-нефть» вплоть до обращения фаз. Для таких регентов характерным является более высокое сродство к водной фазе, чем к органической, и способность к образованию мицелл в водной фазе [19]. Таким образом, 40\%-ная форма реагента - деэмульгатора ЭЖК в нефрасе относится к деэмульгаторам 2 типа, так как способна образовывать критические эмульсии в воде и гексане. Об этом свидетельствует высокое значение оптической плотности $\mathrm{D}$ их растворов, особенно при температуре $20^{\circ} \mathrm{C}$ (кривая 3). Но по мере разбавления готовой формы 


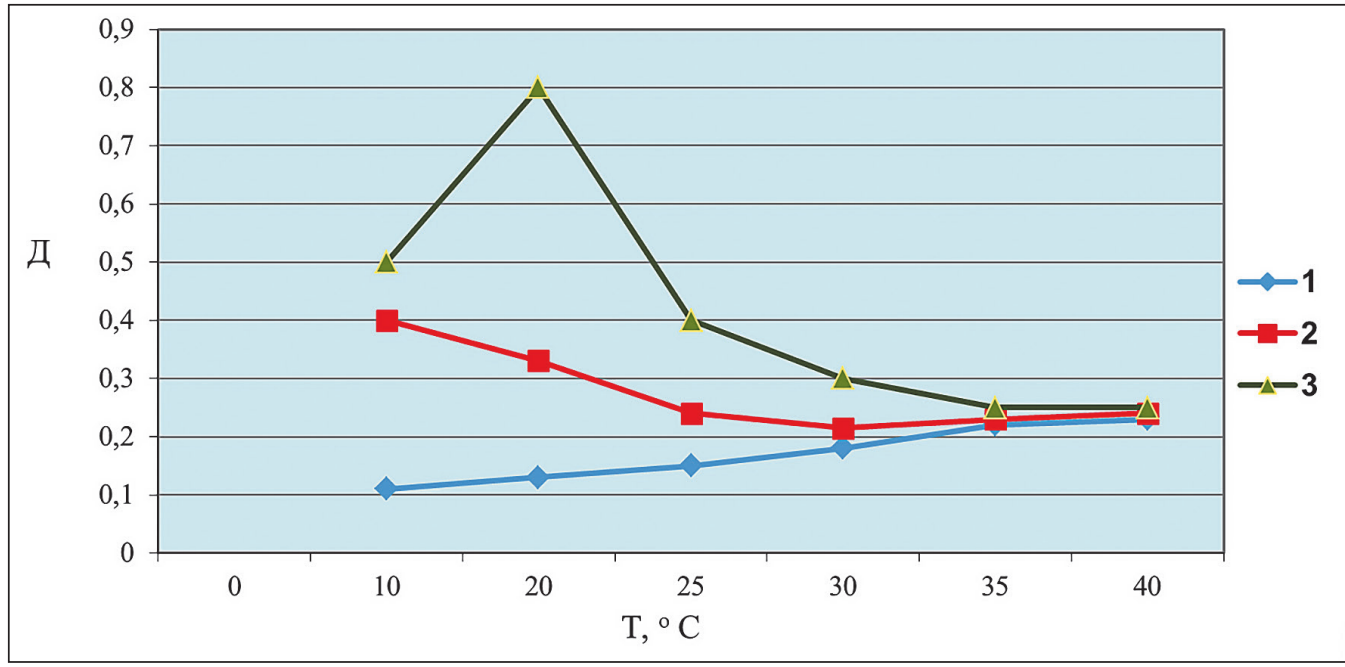

Рисунок 4 - Зависимости оптической плотности от температуры ввода реагента ЭЖК для растворов в гексане. Концентрация реагента ЭЖК,\%: 1 -10; 2 - 20; 3 - 40

реагента растворителем нефрасом уменьшается количество частиц дисперсной фазы в его растворах в гексане, растворы становятся все более прозрачными, величина D уменьшается (кривые 2 и 3 ).

В результате 10\%-ная готовая форма этого реагента в нефрасе образует в гексане уже гомогенные растворы, а в воде не растворяется, что свойственно деэмульгаторам 4 типа. Эти данные свидетельствуют о том, что скорость разрушения эмульсии с 10\%-ной формой реагента ЭЖК характеризует эффект лишь от адсорбционного механизма вытеснение природного деэмульгатора. Несмотря на черезвычайно высокую поверхностную активность этого реагента, снижающего поверхностное натяжение почти до нуля, его деэмульгирующая способность оказывается ниже, чем у $40 \%$-ной формы. Повышение скорости разрушения эмульсий с 40\%-ной формой по сравнению с 10\%-ной связано с экстракцией природных деэмульгаторов дисперсной фазой критической эмульсии. Насколько значителен этот эффект можно судить по тому, что использование 30 г/т деэмульгатора в виде 20\%-ной формы оказывается менее эффективным, чем 10 г/т 40\%-ной формы. Таким образом, данные рисунка 4 демонстрируют насколько значительно повышается эффективность деэмульгатора за счет присутствия компонентов, придающих составу синергетический эффект, если его готовая форма приобретает способность образовывать в растворах критические эмульсии.

Таким образом, на основе экспериментальных данных показано, что полученный авторами состав обладает высокой эффективностью при обезвоживании и обессоливании водонефтяных эмульсий при расходе 30-35 г/т нефти, улучшает реологические свойства продукции скважин в процессах подготовки нефти. Данное решение позволяет решить поставленную задачу и обеспечивает следующие преимущества по сравнению с прототипом: скорость деэмульгирования нефтяных эмульсий повышается по сравнению с прототипом, этерифицированные жирные кислоты, соапсток и растворитель Нефрас Ар 120/200 при их совместном присут- 
ствии в композиции создают синергетический эффект, улучшающий реологические свойства подготовленной нефти.

Синтезированный на основе жирных кислот деэмульгатор является относительно недорогим, так как он получен на основе отходов масложировой промышленности - жирных кислот вакуумной дистилляции хлопкового соапстока. По эффективности обезвоживания реагент не уступает известным составам для деэмульсации парафинистой нефти, и, поэтому расширение его функциональных возможностей без снижения деэмульгирующей способности представляет практический интерес на месторождениях по добыче и подготовке нефти.

Данные исследования выполнены при поддержке Комитета науки Министерства образования и науки Республики Казахстан (грант АР08857586).

\section{ЛИТЕРАТУРА}

1 Надиров Н.К. Как сделать Казахстан самой конкурентоспособной и передовой нефртяной страной мира // Нефть и газ. - 2020. - № 3-4. - C.7-50. [Nadirov N.K. Kak sdelat' Kazahstan samoj konkurentosposobnoj i peredovoj neftyanoj stranoj mira // Neft' i gaz. - 2020. - № 3-4. - S.7-50].

2 Moldabaeva G.Zh., Baibotaeva S.E., Nadirov K., Zeygman Y., Sadyrbaeva A.S. Reagent preparation for oil treatment and its use in the process of dehydration // Jr. of Industrial Pollution Control. - 2017. - 33. - P. 1075-1084.

3 Бойко Г.И., Любченко Н.П., Маймаков Т.П., Шайхутдинов Е.М., Оразбекулы Е., Сабдалиева М.К., Игнатович А.В. Химические реагенты для подготовки нефтей к транспорту. Научно-технологическое развитие нефтегазового комплекса: доклады восьмых международных научных Надировских чтений. - Алматы, 2010. - С. 150-155 [Bojko G.I., Lyubchenko N.P., Majmakov T.P., Shajhutdinov E.M., Orazbekuly E., Sabdalieva M.K., Ignatovich A.V. Himicheskie reagenty dlya podgotovki neftej k transportu. Nauchnotekhnologicheskoe razvitie neftegazovogo kompleksa: doklady vos'myh mezhdunarodnyh nauchnyh Nadirovskih chtenij. - Almaty, 2010. - S. 150-155.].

4 Wu Tong, Wang Xingwang, Zhang Yunanetal. Study on the Dehydration Process of Aging Oil by Demul sifier Modified With Nanometer-Silicion // Contemporary Chemical Industry. - 2013. - № 42(11). - Р. 1488-1490.

5 Надиров Н.К. Высоковязкие нефти и природные битумы. В 5 т. Т.2. Добыча. Подготовка. Транспортировка. - Алматы: «Ғылым», 2001. - 344 с. [Nadirov N.K. Vysokovyazkie nefti i prirodnye bitumy. V 5 t. T.2. Dobycha. Podgotovka. Transportirovka. - Almaty: «Fylym», 2001. - 344 s.].

6 Sun Zhenggui. Application of Polyether Demulsifier TA1031 Modified by Nano-AI2O3[J] //Journal of Petrochemical Universities. - 2008. - № 21(3). - P. 9-12.

7 Семихина Л.П., Перекупка А.Г., Плотникова Д.В., Журавский Д.В. Повышение эффективности деэмульгаторов путем получения их наномодификаций // Вестник Тюменского государственного университета. - 2009. - № 6. - C.88-93. [Semihina L.P., Perekupka A.G., Plotnikova D.V., Zhuravskij D.V. Povyshenie effektivnosti deemul'gatorov putem polucheniya ih nanomodifikacij // Vestnik Tyumenskogo gosudarstvennogo universiteta. - 2009. - № 6. - S. 88-93.].

8 Башкирцева Н.Ю. Композиционные деэмульгаторы для подготовки нефти: авторефрерат канд. техн. наук. - Казань. - 1996. - 34 с. [Bashkirceva N.YU. Kompozicionnye deemul'gatory dlya podgotovki nefti: avtoreferat kand. tekhn. nauk. - Kazan'. - 1996. - 34 s.]. 
9 Инновационный патент № 32196 РК. Композиционный деэмульгатор / Надиров К.С. Опубл. 2017. [Innovacionnyj patent № 32196 RK. Kompozicionnyj deemul'gator / Nadirov K.S. Opubl. 2017.].

10 Инновационный патент № 3290 РК. Состав для глубокого обезвоживания и обессоливания нефти / Надиров К.С., Капустин В.М., Приходько Н.А., Сатаев М.И. Отарбаев Н.Ш. Опубл. 2018. [Innovacionnyj patent № 3290 RK. Sostav dlya glubokogo obezvozhivaniya i obessolivaniya nefti / Nadirov K.S., Kapustin V.M., Prihod'ko N.A., Sataev M.I. Otarbaev N.SH. Opubl. 2018.].

11 Надиров К.С., Жантасов М.К., Бимбетова Г.Ж., Ерменов С.М., Жусупалиев М.А., Отарбаев Н.Ш. Оксиэтилирование жирных кислот гудронов хлопкового масла для получения ПАВ деэмульгирующего действия. Материалы за X Международна научна практична конференция «Найновите научни постижения-2014», Т. 33. Технологии. София.: «БялГРАД-БГ» ООД , 2014. - С.69-74.

12 Надиров К.С., Жантасов М.К., Бимбетова Г.Ж., Орынбасаров А.К., Ерменов С.М., Шегенова Г.К., Калменов М.У., Зият А.Ж. Выбор метода экстракции свободных жирных кислот из смеси компонентов госсиполовой смолы // Materialy XI mezinarodni vedeckokonference «Aktualnivy mozenostivedy - 2015». - Dil 6. Lekarstvi. Biologickevedy. Chemieachemick a technjjijgie. Ekologie. Zemedelstvi.: Praga. Publishing House «Education and Scitnce» C.51-56.

13 Арутюнян Н.С., Корнена Е.П., Янова Л.И. Технология переработки жиров/ Под ред. Профр. Н.С. Арутюняна. 2-е изд., перераб. и доп. - М.: Пищепромиздат, 1998.- 452 с. [Arutyunyan N.S., Kornena E.P., YAnova L.I. Tekhnologiya pererabotki zhirov/ Pod red. Prof. N.S. Arutyunyana. 2-e izd., pererab. i dop. - M.: Pishchepromizdat, 1998.- 452 s.].

14 Беззубов Л.П. Химия жиров. 5-е изд. - М.: Пищевая промышленность, 1995. - 289 с. [Bezzubov L.P. Himiya zhirov. 5-e izd. - M.: Pishchevaya promyshlennost', 1995. - 289 s.].

15 Сомов В. Е. Стратегические приоритеты российских нефтеперерабатывающих предприятий. - М.: ЦНИИТЭнефтехим, 2002. - 292 с. [Somov V. E. Strategicheskie prioritety rossijskih neftepererabatyvayushchih predpriyatij. - M.: CNIITEneftekhim, 2002. - $292 \mathrm{~s}$.].

16 Плешакова Н.А. Гидрооблагораживание масляных фракций нафтено-ароматической нефти // Нефттехимия. - 2008. - № 5. - C. 344-351. [Pleshakova N.A. Gidrooblagorazhivanie maslyanyh frakcij nafteno-aromaticheskoj nefti // Neftekhimiya. - 2008. - № 5. - S. 344-351.].

17 Заклева Р.P. Получение базовых масел III группы качества по классификации АРІ из тяжелого углеводородного сырья с применением гидрокаталитических процессов // Вестник Казанского технологического университета. - 2014. - № 17. - С. 209212. [Zakleva R.R. Poluchenie bazovyh masel III gruppy kachestva po klassifikacii API iz tyazhelogo uglevodorodnogo syr'ya s primeneniem gidrokataliticheskih processov // Vestnik Kazanskogo tekhnologicheskogo universiteta. - 2014. - № 17. - S. 209-212.].

18 Надиров К.С., Жантасов М.К., Бимбетова Г.Ж., Орынбасаров А.К. Разработка аппаратурно-технологического оформления процесса оксиэтилирования жирных кислот госсиполовой смолы // Национальная ассоциация ученых. - 2015. - №3(8). - С. 160163. [Nadirov K.S., ZHantasov M.K., Bimbetova G.ZH., Orynbasarov A.K. Razrabotka apparaturno-tekhnologicheskogo oformleniya processa oksietilirovaniya zhirnyh kislot gossipolovoj smoly // Nacional'naya associaciya uchenyh. - 2015. - №3(8). - S. 160-163].

19 Зимон А. Д. Коллоидная химия. - М.: Агар, 2003. - 320 с. [Zimon A. D. Kolloidnaya himiya. - M.: Agar, 2003. -320 s.]. 